\title{
Feminist Epistemologies of Situated Knowledges: Implications for Rhetorical Argumentation
}

\author{
JAMES C. LANG
}

\author{
James C. Lang \\ Associate Faculty \\ Department of Theory and Policy Studies \\ OISE/The University of Toronto \\ clo 105 Sunset Boulevard \\ Thornbury, Ontario, \\ Canada, $\mathrm{NOH} 2 \mathrm{PO}$ \\ Email:jim@jlang.com
}

\begin{abstract}
In the process of challenging epistemological assumptions that preclude relationships between knowers and the objects of knowing, feminist epistemologists Lorraine Code and Donna Haraway also can be interpreted as troubling forms of argumentation predicated on positivist-derived logic. Against the latter, Christopher Tindale promotes a rhetorical model of argument that appears able to better engage epistemologies of situated knowledges. I detail key features of the latter from Code, especially, and compare and contrast them with relevant parts of Tindale's discussion of context on the rhetorical model, and I suggest ways that his work could be expanded to accommodate rhetorical implications of situated knowledges.
\end{abstract}

Resumé: En critiquant les suppositions épistémologiques qui excluent les relations entre celui/celle qui connait et les objets connus, les épistémologistes féministes Lorraine Code et Donna Haraway avancent une forme d'argumentation troublante qui repose sur une logique dérivée du positivisme. Christopher Tindale avance contre cette logique une représentation rhétorique des arguments qui semble être capable de mieux engager les épistémologies de connaissances situées. Je présente en détail des traits principaux de l'épistémologie de Code, et les compare et les mets en contraste avec des idées pertinentes de la discussion de Tindale sur le contexte de la représentation rhétorique. Je suggère des façons que son œuvre peut élargir et accommoder des implications rhétoriques des connaissances situées.

Keywords: argumentation, Code, feminist theory, rhetorical argumentation, situated knowledges, Tindale.

\section{Introduction}

Feminist meta-epistemological work offers new ways of thinking about knowledge that challenge traditional argumentation theory, especially where the latter is grounded in what Janice Moulton describes as the "Adversary Paradigm" (1983). Various versions of the latter remain so embedded in philosophical discourse that they 
continue to frame forms of argumentation that many feminist epistemologists seem compelled to use, even while attempting to demonstrate their limitations. This illustrates the paradox discussants often encounter when they attempt to engage traditional epistemologists ${ }^{1}$ with feminist epistemologies that challenge key assumptions about knowledge and - by extension - traditional approaches to philosophical argumentation.

Suggested by Chela Sandoval's "oppositional consciousness" (2004) and developed by Donna Haraway (2004/1988) and Lorraine Code, especially (2006), " "situated knowledges" describes a range of materialist understandings of knowledge, knowers and knowing that challenge universalist, positivist-derived, epistemological assumptions that all knowers are effectively interchangeable and that knowledge exists independently of them. On that view, knowledge claims are validated or invalidated by examining objective evidence and stripping away subjective "interference"aspects of the claim that turn on non-universalizable specificities of the claimant's subjectivity. ${ }^{3}$ In contrast, situated knowledges are understood to be entirely constructed and embodied, just as each individual's subjectivity is constructed and embodied. Knowledge cannot be transmitted or received intact, but rather is constructed uniquely in each person, primarily via social intercourse, formal and otherwise. The ways in which persons are situated extend beyond geographical, social, and cultural locations to include the specific ways each person has constructed knowledge about knowledge and about what it means to know. In contrast to some more traditional epistemologists who may agree that knowledge is understood differently by different people, Code and Haraway, among others, claim that knowledge simply does not exist independently of embodied knowers; that each knower therefore embodies different knowledges - however similar they may discover them to be on examination and conversation. In other words, the positions held by those who assume a positivist-derived theory of knowledge would appear to be fundamentally incommensurable with those espousing versions of situated knowledges. Therefore, the forms that discussions around these issues take is crucially im-

\footnotetext{
${ }^{1}$ As I use it here and throughout this paper, this term refers to epistemologists who assume a necessary separation between the knower and the object of knowing/knowledge — often including the view that knowledge transcends individuals. ${ }^{2}$ Other feminists employ various versions of situated knowledges and I do not intend to suggest that Code and Haraway represent a synthesis of views on this subject. I do claim, however, that many feminist theorists would coalesce around the core features of situated knowledges as I present them here.

${ }^{3}$ Testimony, for example, is suspect in this critico-logical model, where the following would not be considered germane to the examination of evidence in evaluating a knowledge claim: "I can testify to the validity of this racist claim because I am Black."
} 
portant for constructive engagement of those espousing these contrasting ideas.

Some recent developments in argumentation theory that focus on the arguer and on context promise ways of reviving rhetorical/dialectical forms of philosophical argumentation that appear to offer a better prospects for a engaging with feminist epistemologies of situated knowledges. I interpret Michael Gilbert's work on coalescent argumentation (1997), which suggests goals of agreement as opposed to the negative reductionist "critico-logical" zero-sum goals of establishing winners and losers, as representing important progress. Christopher Tindale's case for a move to a rhetorical model of argument (1999) focuses on legitimizing context and the situation of the arguer, which is also of central importance to many feminist epistemologies. Tindale appears to have made progress in helping to resuscitate rhetorical argumentation by situating argumentative reasoning, focusing on the role and particularity of audience and on the contexts and subjectivities of the arguers. Although he does not make the connection himself, I find his explication of context can be linked to the notion of situated knowledges, especially as taken from Code and Haraway. ${ }^{4}$ As important as Tindale's advancements are, however, I find they cannot accommodate fully the epistemological implications of Code's and Haraway's conceptions. Importantly, nevertheless, Tindale's work helps to frame some ways Code's and Haraway's accounts can enrich rhetorical argumentation, perhaps, radically.

In this paper, I examine the ways that epistemologies of situated knowledges (occasionally, hereafter, for brevity, ESK), taken from Haraway and Code primarily, challenge and transform traditional conceptions of knowledge and simultaneously call into question the positivist-derived forms of argumentation that are bound

\footnotetext{
${ }^{4}$ Many feminists balk at attempts to synthesize their collective works, claiming that doing so reduces and weakens their varied positions, whereas taking them in the aggregate offers more and better ways to address their concerns. In focusing primarily on the work of Lorraine Code, I do not suggest that she represents all feminist epistemologies; rather, I offer my interpretation of hers - and Haraway's - work with the hope that there will be sufficient points of agreement with a range of readers to make the effort worthwhile. I choose Code's epistemological work primarily because, unlike some feminist theorists, she does not dismiss all possibilities of objectivity, nor does she discount scientific successes built on an epistemology that she critiques as limited, rather than universally applicable. In her work, Code acknowledges the influence of pioneering research by a broad range of feminist theorists. Code's work to date includes four major books: Epistemic Responsibility (Code, 1987), the generative, What Can She Know?: Feminist Theory and the Construction of Knowledge (Code, 1991), Rhetorical Spaces: Essays on Gendered Locations(Code, 1995) and Ecological Thinking: The politics of epistemic location (Code, 2006). Code draws on Donna Haraway's work on situated knowledges, especially her immensely generative (nearly 3,000 citations to date) paper, Situated Knowledges: The science question in feminism and the privilege of partial perspective (Haraway, 2004/1988).
} 
up with them. ${ }^{5}$ I suggest that Tindale's rhetorical model of argumentation tilts favorably toward situated knowledges, but also that his attention to the subject, or arguer, requires significant expansion if it is to include multiple implications of difference, a core feature of ESK. ${ }^{6}$ So enriched, I suggest that rhetorical argumentation could include novel new and more effective techniques which I extrapolate from the works of feminist theorists Maria Lugones, Maureen Ford, and Jennifer Logue. I suggest that these could help to engage philosophers who are able to deflect engagement via reductionist, positivist-derived argumentation. Predicated on assumptions of socially constructed subjectivity, rhetorical argumentation could include playfulness and strategies that press personal comfort zones toward the goal of stimulating harm-reducing action. The latter is key when knowledge construction practices are understood as inherently moral activities, as they are on ESK, and the goal of argumentation shifts from cognitive realignment (intellectual acquiescence to the winner's argument) to the goal of coalescence/agreement leading to action - ways to reduce the harms of oppressive knowledge construction practices. As Tindale points out, "argument is not just a tool for resolving local disputes, but is instrumental in the improvement of human communities" (Tindale, 1999, p. 203).

In arguing for a move to rhetorical argumentation, Tindale notes that, unlike argumentation in formal logic where the arguer is assumed to be separate from the argument (just as the subject is separate from the object of knowing), rhetorical argumentation legitimizes features of the arguer as part of the equally legitimized context in which the argument takes place. The separation of the assertion from the person making it loses the person's sense of commitment to the assertion, says Tindale, and "thought that leads to action is different from the statements in a scientific system because it moves the person to modify the self on the basis of thought" (p.71). Tindale's concern lies mostly with the involvement of emotion, expression, and even "attention to an author's beliefs" in rhetorical argumentation (p. 78). I suggest that by acknowledging the relevance of the particularities of context - of the

\footnotetext{
${ }^{5}$ I refer here to positivism in broad strokes, implying a scientistic understanding of knowledge as primarily, if not exclusively, reducible to expressed propositional formulations. To qualify as knowledge, these claims must be justified by impartial examination of universally accessible relevant evidence, as well as by stripping away any subjective particularities of its knowers (since these cannot be shared universally). Knowledge is equally accessible by all individuals in part because it transcends individuals - it exists independently of persons.

${ }^{6}$ On ESK, differences are not merely superficial observations about cultural and social location; they include the dynamic intersection of a person's history, affect, sense of being a knower among many particularities. ESK is an acknowledgment, first and foremost, of multiple differences among knowers and of similarly different ways of knowing by knowers.
} 
arguer, especially-he creates openings, "rhetorical spaces"7 for Code's and Haraway's radical extension of situatedness, which I sketch next.

\section{Gendered knowledge and socially constructed subjects}

The single most important point of departure between Lorraine Code and many traditional epistemologists lies in the latter's explicit and implicit assumptions that knowledge transcends knowers. All humans are assumed able to employ an innate rational autonomy to access and understand universally accessible objective evidence through which they are able to adjudicate knowledge that is "worthy of the name" (true for everyone). Individual knowers, then, are understood to be universally interchangeable. On this view rational autonomy is innate; it can develop in everyone in the same way, requiring only courage to release its potential. ${ }^{8}$ Thus, on assumptions of rational autonomy, knowledge is presumed to be derived from a neutral, impartial location. Against this notion, Lorraine Code claims that "the invisible, voiceless, knowing subject in mainstream epistemology and philosophy of science has a voice after all: it is presumptively male. It is no wonder that the knowledge he produces is androcentric, for it derives from typically male experiences" (1995, p. 173).

When Code, especially, established the epistemic relevance of gender, in part by demonstrating the masculinist origins of western philosophy, she also exposed masculinist features of philosophical discourse. ${ }^{9}$ The use of forced dichotomies, as just one example, reveals masculinist privilege. ${ }^{10}$ In simple terms, dichotomies can thus be understood as constructed to serve their masculinist creators' epistemology, evidenced by the epistemic privileging of " $\mathrm{A}$ " (predominantly associated with masculine traits) over "B" (predominantly associated with feminine traits) in forced dichotomous choices; for example: rational/emotional; theory/practice; objective/subjective; universal/particular; mind/body; abstract/concrete. This categorization also aligns epistemically valid considerations against their-female-invalid or lesser counterparts. According to Code, "Dichotomies are especially problematic in that they posit

\footnotetext{
${ }^{7}$ As Code describes the term in her book of the same title, rhetorical spaces are "fictive but not fanciful or fixed locations" where there is an "expectation of being heard, understood, taken seriously" (Code, 1995, pp. ix-x).

${ }^{8}$ As Kant famously exhorted, "Sapere aude!" ("Dare to know!") (Kant, 1959)

${ }^{9}$ I am not suggesting Code was the first philosopher to do so, but her book, What Can She Know, is considered perhaps one of the most extensive and widely used work on this issue; see: (Code, 1991)

${ }^{10}$ Evelyn Fox Keller demonstrated this compellingly in her generative article, "Gender and Science." (Keller, 1983)
} 
exclusionary constructs, not complementary or interdependent ones that could shade into one another or function as 'mixed modes' rather than absolutes" (Code, 1995, p. 29). ${ }^{11}$ Dichotomies, derived from masculinist constructs, stand in opposition to feminist lived experience; as Nancy Hartsock puts it, "If material life structures consciousness, women's relationally defined existence, bodily experience of boundary challenges, and activity of transforming both physical objects and human beings must be expected to result in a world-view to which dichotomies are foreign." (Hartsock, 2004 (1983), p. 45).

Where Code identifies the masculinist - and thus, limited, rather than universal-features of knowledge as received from modern philosophers, Janice Moulton points out parallel masculinist features of philosophical argumentation. She identifies as masculinist the "conflation of aggression with success," which is constitutive of the Adversary Method (capitalized in Moulton) that "dominates the methodology and evaluation of philosophy" (1983, p. 153). I suggest that Moulton's views on the limitations of the dominant mode of argumentation converge with Code's similar conclusions about the masculinist origins and features of epistemology. Both conclusions would augment Tindale's explication of context in rhetorical argumentation. However, "situatedness" 12 for Code and Haraway has an important feature, possibly better described as a third dimension, that of the socially constructed subject.

\section{Rational autonomy as an idealized fiction}

The assumption of uniformity among individuals qua knowers is implicit in traditional epistemology as well as in formal logic, which permits their fungibility: Knowers are interchangeable. Any knower is innately capable of assessing any specific knowledge claim and further, is capable of so doing in a solitary fashion. Rational autonomy represents the defining epistemological feature of the knower as predicated on Kant (Kant, 1934), a claim that is roundly rejected by Code and other feminist theorists. For example, Catriona Mackenzie and Natalie Stoljar argue against notions that agents are causally isolated from other agents and that agents' senses of themselves are independent of the family and community relationships in which they participate. They treat as fiction the

\footnotetext{
${ }^{11}$ Parts of this paragraph, modestly revised, appear as well in a forthcoming paper for Educational Theory.

${ }^{12}$ I use this odd - possibly misguided - construction occasionally to differentiate the ways individuals are situated in the context of situated knowledges from the common term "situation" that has similar but possibly misleading connotations when used in this context.
} 
idea that agents' essential properties (that is, their natures, or metaphysical identities) are intrinsic and are not comprised, even in part, by the social relations in which they stand $(2000 \mathrm{~b}, \mathrm{p} .7)$. With Annette Baier they claim that persons do not develop independently of other persons: "Persons are essentially successors, heirs to other persons who formed and cared for them, and their personality is revealed both in their relations to others and in their response to their own recognized genesis" (p. 7). Lorraine Code argues that the discrete individual is better understood as a social construction and she agrees with Baier that insofar as a person acquires her sense of personhood necessarily from others she is not a "first-person singular" as much as she is what Baier calls a "second-person" to other second-persons. The knowledge of oneself as a person does not arise a priori but rather through social intercourse with her community. Thus, in Code's words,

There can be no sense in assuming that [person] grow naturally to autonomous self-sufficiency, only thenperhaps, cautiously, incidentally, or as an afterthought - to participate in intimate relationships....A human being could not become a person, in any of the diverse senses of the term, were she or he not in "second person" contact from earliest infancy....Autonomy and self-sufficiency define themselves against a background of secondpersonhood....[citing Baier] "persons are the creation of persons." (1991, p. 85)

Catriona Mackenzie describes us as:

social creatures who are formed and transform ourselves in our intimate and non-intimate relationships with other people. We become persons and live our lives in particular social, cultural, and historical communities. Our sense of our lives as temporal, our points of view, our selfconceptions, and our values, are therefore shaped by these relationships and these communities. (2000a, p. 139)

Nancy Tuana explicates further the epistemological ramifications of embodiment: "At an epistemological level the embodiment hypothesis is the belief that our concepts emerge from, and are in part formed by, the particularities of our bodies and of our bodily interactions with the physical world" (2001, p. 229). The idea that our bodies are intimately involved with our constructed knowledges and, thus, its construction of our subjectivity, stands in stark contrast to traditional epistemology, which assumes that identical truths can be achieved by all rational knowers. The idea that we can detach ourselves from our embodiment and see impartially so as to 
make universally-applicable claims is rendered incoherent. Not being gods we cannot perform the "god-trick," as Donna Haraway famously phrases it, "of seeing everything from nowhere" (2004/1988, p. 86). Our perspectives are necessarily embodied, always views from embodied subjects who are situated in multiple ways.

\section{Context: More than a location from which to know/argue}

Tindale discusses and endorses the relevance of context to rhetorical argumentation that includes particularities about the arguer and the audience; he claims a role for emotion, attention to varied ways of expressing speech-acts and for the background and beliefs of the arguer and audience (1999, pp. 76-79). His purpose is to show the ways the argument is not separable from the arguer and the audience. Although he recognizes the importance of interpreting content, he does not go the additional step to claim that the content of rhetorical argumentation is also not separable from its knowers. When content (knowledge) is bound up with and constitutive of arguers/knowers, attention to context would need to recognize the situatedness of each arguer and of each individual constituting an audience. This would require abandoning assumptions of uniformity all the way down. Tindale promotes the legitimacy of attending to an arguer's beliefs, but, on Code, these extend to including what the arguer believes about knowing and knowledge - what each believes it means to know. In other words, context is more than superficial embellishment of the particularities of participants in philosophical discourse, or of locating individuals historically, geographically, sexually and so on. It must also work to accommodate/map the unique dynamic situatedness of each participant in a philosophical discussion. Situation, as Code tells us:

is not just a place from which to know, as the language of "perspectives" might imply, indifferently available to anyone who chooses to stand there. Situation is itself $a$ place to know whose intricacies have to be examined for how they shape both knowing subjects and the objects of knowledge; how they legitimate and/or disqualify knowledge projects; how they are constituted by and constitutive of entrenched social imaginaries, together with the rhetoric that holds them in place. It is an achieved epistemic stance, knowledgeably chosen as a place that can be mapped to facilitate responsible knowing. (2006, pp. 4041) 
Thus, consideration of context when applied to the arguer could include discussions around fundamental epistemological questions, such as those raised by Code, above. Of these, the question about legitimizing or disqualifying knowledge projects looms particularly large relative to the reluctance of some traditional epistemologists to engage with feminist epistemologies. I return to this aspect, later, but first, I touch on the related issue of constructed knowledges.

\section{Challenges to transmissible knowledge and dislocated truths}

Assumptions of transcendent knowledge continue to hold sway among epistemological traditionalists such as Harvey Siegel, for example, who explicitly describes the transmission of knowledge from teacher/text to students as a key aim of education (2008, p. 123). This model allows teachers (and/or arguers) to assume epistemic uniformity among students (qua audience) across their apparent differences; some will grasp more of it, some less and some will misunderstand it, but the assumption remains that it retains its discrete quality of truth independently of its knowers. Against such assumptions of sameness that allow persons to assume uniformity in the way the other understands similarly-expressed claims stands the ESK claim that knowledges are constructed, rather than transmitted; that this process occurs most often dialogically, conversationally, relationally - and interdependently - among persons whose identities are also constructed and therefore situated. Situatedness describes the features of the dynamic locus of a person's sense of self as it flickers and changes - a nexus of intersecting subjective particularities. On this view, knowers and their knowledges are necessarily multiply-situated historically, politically, culturally, linguistically and sexually among many possibilities. Thus, transmission of knowledges so constructed from one person to another would require, impossibly, the transmission of a person's situatedness - the ability to not merely pretend to be in another person's "shoes" but, effectively, to be another person.

Furthermore, when knowledges are understood as situated and constructed, rather than transcendent and transmissible, the same assumptions apply to evidence in support of knowledge claims. On ESK, facts do not announce themselves, or, as Lorraine Code puts it, "there are no dislocated truths" (1995, p. 42). Observations about objects need to be designated as facts for a purpose. To suggest that all knowers will accept as neutral or even recognize evidence that has been chosen and presented for a specific purpose, or that knowers need not interrogate evidence brought by science is no longer an acceptable assumption. Empirical claims would not be immune from interpretive methodologies, according to Lorraine Code, who advocates a stance described as - paradoxically, in tra- 
ditionalist terms_-"negotiating empiricism."13 This approach allows for contesting and interrogating otherwise uncontested knowledge claims, and that respects testimonial evidence and knowledges constructed through the interplay, dialogue, and specificities of the circumstances within which the claims are made, justified and contested (Code, 2006, p. 6).

Thus, to Tindale's list of factors to be considered as context for argumentation, ESK would need to add the context of evidence, scientific or other, since evidence would not be considered relevant without explanations of how and why it has been assembled qua evidence. This speaks to the moral feature of knowledge construction practices, addressed below, since arguers would be held accountable not merely to the evidence, but for the evidence.

\section{Interpretation and rhetorical argumentation}

Tindale addresses the importance of interpretation, which I suggest links closely to the issues raised by ESK. He includes interpreting the intentions and beliefs of the arguer, but adds that "it plays a role not just in deciding how the content of an argument should be interpreted, but also in determining the type of argument-as-product involved in the argumentation" (1999, p. 78). Will the argumentas-product be a deduction? This matters a great deal when, as Moulton claims, in formal logic any meanings not "assimilated into the deductive model" are ignored (1983, p. 155).

Interpretation is fundamental to argumentation as it would unfold on ESK. Using Susan Hekman's work, Lorraine Code focuses on "the interpretive character of all human knowledge" (1995, p. 133). No doubt Tindale, who also espouses the legitimacy of emotion in rhetorical argumentation (1999, pp. 72-73) would agree with Code's claim that "interpretive epistemology" involves empathy, which is, in Code's terms, a key tool in interpreting relationships with differently situated others (Code, 1995, p. 130). An empathetic relationship requires continual reinterpretation, facilitating authentic knowledge-sharing/generating between particular persons. ${ }^{14}$ Interpretive exchanges "focus on particularity, context, texture; they resist monologic, abstract formulations to maintain their meanings - the stuff of which their inquiry is made....with their commitment to ongoing interpretation and reinterpretation, they escape the tyranny of obdurate privileged access claims" (1995, p. 135). Participants in argumentation so structured would acknowl-

\footnotetext{
${ }^{13}$ Paradoxically because empirical claims are traditionally understood to either be proved unequivocally by their supporting evidence or not, subject only to changes required by subsequent new evidence. See Code: (Code, 2006, p.100)

${ }^{14}$ Notwithstanding the dangers of arrogant perception-discussed later in this paper-inherent in attempts to empathize with differently-situated others.
} 
edge listeners as participating equally with speakers while recognizing the dynamic aspects of both positions. Again, Tindale would likely concur, since, as he says, "there is no discourse without audience, there is no argumentation without rhetorical effect" (1999, p. 84). On the preceding work, however, Tindale does not imply what ESK claims, that the effect of rhetoric would involve the continual construction and reconstruction of knowledges, themselves, as embodied in their situated knowers.

\section{Re-imagining relativism}

Both Tindale and Code are aware that their arguments are subject to charges of relativism and both challenge sedimented negative connotations with which relativism is generally regarded by traditional philosophers. Space will not permit a full exegesis of their positions on this important subject, but a brief explication of both is likely called for at this juncture.

Tindale acknowledges many extant versions of relativism but he chooses to focus on the three that he considers most relevant to implications for rhetorical argumentation. The first and most serious, in Tindale's view, is the charge of total subjectivism-that without the possibility of objective truth there could be no agreement among arguers. On this claim, each participant in a philosophical argument would hold an unassailable position, since each would represent an equally true opinion. There being no truth independent of the arguers, agreement would be impossible. Tindale disagrees, saying that the greater problem lies in the absolutist's position, where "criticism directed from a position of truth, or expected truth, will not value the strengths and weaknesses of people's proposals" (1999, p. 98). This does not imply that each person's proposals are equally defensible. "Simply put, it does not preclude agreement on what is the case. People from different perspectives can dispute the reasonableness of their judgments. The rhetorical perspective on argumentation facilitates this" (p. 98). Unlike the absolutist's assumption that argument ends when "the truth" is established, rhetorical argumentation necessarily remains unfinished, subject to further and better understandings of the arguers' positions.

The second criticism claims that in committing to a particular position arguers would be engaged in performative contradiction, demonstrating the common condemnation of relativism as "anything goes." Tindale suggests that this critique deserves its "naïve relativism" tag, since, tied necessarily to its particular context, any relativism is necessarily so constrained. Anything, therefore, does not go. Truth, says Tindale, has more than one absolute sense and universalists err in assuming that relativists speak of it in universal 
terms only. Tindale says that "relativism is not a denial of all 'truths,' since the context forms an underlying truth" (p. 99). The criticism fails when more than one meaning for truth is available, which he claims is necessarily the case in contexts of rhetorical argumentation.

Finally, Tindale considers the criticism of moral "quietism," the assumption that in the absence of an absolute determination of truth - who is right and who is wrong-relativists would be unable to justify a position and thus make moral or political decisions based on it. Tindale argues that this position assumes relativists bring opinion without justification. Rather, Tindale argues, "given the diversity of opinions that can be put forward on a position, the relativist insists that the relative merits of each position also be put forward" (p. 99). Arguing from Chaim Perelman, Tindale claims that the "reasonableness of an argument is not bound up with the truth or falsity of its conclusions," noting that "human communities have, as a matter of common practice, adhered to theses that time subsequently proved to be wrong or in need of substantial revision" (p. 100). In other words, truths are not immutable or absolute; they can and do change over time.

Like Tindale, Lorraine Code also claims that the relativist's position is actually stronger than that of the universalist's, and that it can anticipate continuing interpretive possibilities. Code says that "epistemological relativism is a strong position because it creates the possibility of raising questions about the identity of knowers. It opens the way for analyses of the historical, racial, social, and cultural specificity of knowers and knowledge" (1991, p. 19). In other words, a relativist position requires examination of the ways in which arguers are situated - not that testimony should go uncontested or un-interrogated, but that it must be granted the legitimacy it is denied in traditional philosophical discourse. Regarding the "anything goes" charges that claims regarding the truth of relativist principles must be self-refuting, Code counters that such positions tend to emanate from "a conception of relativism that is born more of [the philosophers'] background assumptions and ideological commitments than it is of the practical real-world implications of working from within a relativist position" (1995, p. 186). Similar to Tindale's argument, Code claims that absolutists' talk of truth is question-begging in that it assumes truth to have but one, absolutist sense and that absolutists assume self-proclaimed relativists are using the term in that sense. A relativist truth claim is a "three-term relation," says Code, in which the third term involves a specific location. This contrasts with an absolutist "two-term relation" where a proposition is true "of a certain state of affairs, or of the world." Code says: 
A relativist making a truth claim, then, is asserting that something is true of a certain state of affairs or of the world "for $X^{\prime \prime}$ "in $X$ circumstances," where $X$ stands for one of these local, locational possibilities. Its extension is not limited to $X$, for situated knowers are rarely sealed within or immobilized by their situations: trans-locational discussion - dialogue - occurs all the time and [in physics, for example] sometimes it is productive of remarkably widespread consensus. (1995, p. 198)

In other words, Code is not rejecting scientific objectivity, full stop, but is restricting its scope, rendering its truths relative to the limits of its historicity and to the situations of its claimants and their claims.

$\mathrm{s}$ to the criticism that relativism is politically disarming, that one could construct the world at will and therefore one could not deliver moral prescriptions, Code, similar to Tindale, claims that:

Even the most thoroughgoing of constructivists would recognize that a good construct has to work with, and respect, the available materials. One cannot wish those materials into, or out of, existence; nor do they lend themselves to any and every purpose. On this basis alone, this last objection to relativism fails to carry. It is further disarmed by the equally telling counterclaim that only the supremely privileged could pretend that they have access to the one true story. Only they could assume that they speak from nowhere, and for everyone, to produce perfectly objective knowledge. (1995, p. 193)

Not satisfied to merely meet charges of relativism from traditional philosophers, Code claims feminists should embrace relativism and refuse "to participate in the exclusionary moves, and the disquietude, that every step toward such a benighted position has tended to invoke" (p. 194). Code suggests that the relativist position is an important act of resistance in denying the possibility of the universalist-objectivist alternative, which she sees as "a foundationalist project in epistemology that has served to underwrite the oppressions that permeate and order late-twentieth- century societies" ( $p$. 194). Contra the idea that relativism produces moral quietism, Code contends that:

knowledge is constructed in positions of varying power and privilege... knowers are accountable to a reality that is often quite precisely specifiable, and for the products and consequences of their constructive activities...Thus, I am arguing that a feminist may indeed have to be a relativist 
after all, but in consequence she will be enabled, rather than immobilized. (p. 196)

Code argues that feminist epistemologists should embrace "a mitigated relativism, constrained by objectivity and a commitment to realism" (1991, p. 251), and one that does not preclude moral prescriptions but rather is inevitably moral and political. Code devotes her book, Ecological Thinking, to the idea that truths are made and adjudicated locally - ecologically — on principles of facilitating mutual habitability, are dependent on, rather than weakened by, the particularities of the people and circumstances involved; the truths are relative to them (Code, 2006).

To sum up, the charge of relativism can be met with reimagined ways of understanding the term and its correlative, truth. Code and Tindale concur that traditional critiques from relativism are predicated on just one formulation of truth and that rhetorical argumentation and feminist epistemologies of situated knowledges employ different versions of truth. Charges of relativism, therefore, do not meet Tindale's or Code's work on their own terms and thus do not succeed.

\section{Knowledge, power and politics}

Even a claim to gaining immediate knowledge on viewing the evidence cannot escape the moral obligations that attend the choice of perspective that necessarily accompanies such claims. On ESK the standard claim that seeing is believing remains to be further interrogated to determine whether harms are being done in the claiming, of what type, and to whom. Knowers see through physical eyes, but their situatedness determines the lenses through which they see, the ways they interpret the sensations and how they construct them into knowledge - thus, seeing involves choices whether we are aware of them or not. As Haraway cautions,

One cannot locate in any possible vantage point without being accountable for that movement. Vision is always a question of the power to see-and perhaps of the violence implicit in our visualizing practices. With whose blood were my eyes crafted? (2004/1988, 89-90)

Haraway's profoundly generative question might ask us to reflect, for example, on the photograph of a lynching and of the assumed and acquired morally neutral perspective through which viewers might see the photograph. Such a stance insulates the viewer from the blood of the victims in the photograph, the blood that makes our consumption of the image possible. 
The idea that the act of seeing can do violence effectively highlights the continental divide separating some traditional epistemologists from epistemic responsibilists, like Code, and her contention that knowledge construction practices are never innocent, always moral (1995, p. 135). Tindale, at minimum, appears sympathetic to the possibility of the moral implications of argumentation in acknowledging its goal of generating action for "the improvement of human communities" (Op. cit., 1999, p. 203). On ESK knowledge construction practices are never impartial, objective or innocent, in part because, as Maureen Ford claims, emphatically, "knowledge is inescapably political" $(1995$, p. 178). When understood in terms of ESK, Tindale's version of the importance of context to rhetorical argumentation would not only need to be expanded in terms of situating its participants but also in describing argumentation as inherently ethical activity, permeated with the potential for harms.

\section{Asymmetrical power and argumentation}

Tindale may well include consideration of power relations among participants in rhetorical argumentation, but he does not seem to address the moral considerations associated with knowledges-asconstructed within contexts of asymmetrical power arrangements. When philosophers assume an objective, impartial god-trick perspective, cleansed of subjective "interference,", they claim a position beyond the reach of moral considerations. Thus, a male, tenured professor, for example, could rightfully assume equal footing with a class of female students in a discussion on gender; a white professor could do the same with a class of African-American students and so on. Of course, the same applies relative to students in conversation with other students or students relative to their professors/teachers. The specificities of asymmetries can be complex, involving age, gender, race, culture, language, and institutional roles, for example. Thus the potential for one person to bring power to bear intentionally in their favour in dominating ways is significant. The potential for the unintentional application of asymmetrical power is perhaps even greater, however, since power relations include multiple effects from social registers such as race, class, gender and geography that operate outside the intentionality of teachers, students and the administration. The degrees and types of harm can vary dramatically and without careful conversation with students, a teacher may not be aware of the damage he or she is inflicting. A teacher's implied hetero-normative assumptions are one

\footnotetext{
${ }^{15}$ As required by Kantian epistemology, because subjective considerations preclude universal applicability.
} 
example, where a teacher's unintentional yet continual and sole use of heterosexual examples, without acknowledging other gender preferences or predilections, can have serious deleterious effects on students who are struggling with their own gender issues.

The potential for harm via asymmetrical power relations would need to be added to considerations of context in Tindale's model, but this is just one kind of moral consideration among many. In advancing ESK, Code, for one, is not undertaking a dry philosophical exercise. She and othersare exposing systems of knowledgeconstruction practices masquerading as objective knowledge assessment that inherently empower and privilege some while disempowering and subjugating others. Herein lies the basis of work on gender equity issues, which is also applicable to many kinds of social justice issues, such as racism. For example, note the attempt to speak from a dislocated, neutral position in the following excerpt from a newspaper article in which a woman describes her position on race:

The way she sees it, all races began in Africa, and while Asians and Caucasians adapted and thrived, other races floundered. "Africans, they really haven't evolved much," she says. "The blacks that we have here [Canada or North America]...we domesticated them. We made them who they are. Otherwise they would still be eating each other and killing each other...It's not racism, it's racialism. There's a difference." (White, 2010)

That her position may be based on bad science does not mitigate her apparent belief that she is not morally responsible for making these kinds of knowledge claims; her claim simply highlights that she declines epistemic responsibility. ${ }^{16}$ Her "matter of fact" presentation assumes innocence in what she likely understands as a straightforward presentation of facts. Similarly, the reporter does not challenge her claims - no doubt assuming their inaccuracy to be self-evident to readers - but he reports them, as if this, too, were a morally neutral activity. His eyes, through which he claims an objective perspective, are crafted with the blood of the subjugated, to answer Haraway's question, cited earlier. His perceived innocence depends on his not recognizing or accepting moral responsibility for his reportage, which hints at the possibility of a privilegeprotecting "will to ignorance," which I will touch on shortly.

In opening the door to the myriad moral considerations that could be relevant to knowledge claims and justifications, feminist epistemologies, as reflected in the work of Code and Haraway, re-

\footnotetext{
${ }^{16}$ Also the title of Lorraine Code's first book, in which she first advances the idea that there exists a social responsibility to "know well." See: (Code, 1987)
} 
move the shelters of objectivity and detachment behind which knowledge claimants have been able to hide. Were the reporter and the woman quoted in the article to assume that knowledge claims are never neutral, always partial, and always carry the potential to harm or oppress, they would have had to first reflect on the many ways these claims can do harm and then either not report them or present them so that they reduce the potential for harm. On ESK, claimants are as responsible for the evidence they present (for choosing it) as they are responsible to the evidence (its reliability and their interpretation of it). Thus, these considerations are not solely related to justificatory criteria but are also focused on the ways the constructions of knowledges can be responsible for harms and oppressions, or be made to resist the same in order to perform liberatory functions.

\section{Dangers of arrogant perception}

Ignorance of privileged access includes ignorance of its purposepower-since these concepts are surely joined at the hip. A proponent of situated knowledges, Maureen Ford has produced work to demonstrate the oppressive use of power through "arrogant perception," which she takes from Marilyn Frye (Frye, 1983). Harms of this type are generated when a teacher, especially, assumes the uniformity of individual students across differences, for example, by claiming to treat everyone equally. Ford claims that when individuals' differences are arrogated - assumed not to exist or based on stereotypes - they are harmed. Ford draws from Melissa Orlie ${ }^{17}$ in this description of arrogant perception:

When one person presumes to adopt another's perspective without reflection on the boundaries of one's own body and location, more often than not one simply imposes the view from there upon another. Indeed, this is the principal way of bolstering one's location and demonstrates the effects involved in doing so. In such cases, one's own view arrogates another's and threatens to violate or do away with it altogether. (2004, p. 339)

Arrogating another's point of view can happen in any powerinfused context, but it takes on even greater moral dimensions in contexts of education where asymmetrical power arrangements are institutionalized. On ESK, teachers and students can also be held responsible for what they choose to know, how they choose to con-

${ }^{17}$ As cited by (Young, 1997) 
struct their knowledges, and for the obligation to "know well,", so that through the performance of their knowledges they avoid inscribing oppressive and dominating scripts. Furthermore, since their identities are involved in a constant dynamic of construction and reconstruction, when students are engaged with teachers in constructing knowledge they are also simultaneously engaged in constructing themselves as knowers. Therefore, teachers need also to share responsibility for the kinds of knowers students become through their relations with one another. Maria Lugones, whose work I discuss below, offers "loving perception" and "nonagonistic playfulness" as suggested approaches that could counter or replace arrogant perception, or as she calls it, the "arrogant eye" (Lugones, 1987).

\section{Engaging the audience via rhetorical argumentation}

The claim that epistemology is inherently moral could be viewed as additive to Tindale's model in that his stated goal for argumentation-which inevitably involves epistemology-is to improve communities. Argumentation, then, as I interpret Tindale, is not merely an exercise in scholarly artifice: Moral considerations are at stake. To that extent-assuming I am interpreting Tindale as he would hope-epistemologies of situated knowledge support his rhetorical model. Epistemologies of situated knowledges, as I've sketched them here, are not offered up merely as one choice among many ways of understanding knowledge, knowing and knowers. Those who espouse ESK claim to see harms where many traditionalists claim there are none to see, which positions proponents of the former as inherently morally motivated to engage the proponents of the latter in their work. Whereas argumentation on formal logic or the "critico-logical" model claims to further and refine scholarly research, those who find ESK compelling are aiming their work at preventing harms that are re-inscribed and perpetuated by assumptions of uniformity and neutral, impartial argument-as-product. Thus, choosing to engage with epistemologies of situated knowledges does not rank as simply one of the choices philosophers may choose to study among equally morally neutral options. The claims of feminist epistemologists like Code cut across all options, arguing that to continue to adhere to and promote the principles that legitimize fictions of epistemological neutrality is to make a philosophically significant choice with serious moral implications.

\footnotetext{
${ }^{18}$ Knowing, in traditional terms, is knowing, full stop. The idea that one can know better goes beyond colloquial use in Code's work, which figures centrally in her first book, Epistemic Responsibility (Code, 1987).
} 
Therefore, expanding and changing the rules of argumentation for philosophical discourse represents important work for many feminist epistemologists. Whereas some in their audience may be engaged by the force of careful, critico-logical argumentation, it seems that others will use similar techniques to escape engagement by reducing important details and complexities to logicallyrefutable propositions. In what space remains, I present two examples drawn from implications of situated knowledges. The first, more detailed, example involves Maria Lugones's notion of nonagonistic "playfulness" and "world traveling," presented in two sections. I link Lugones's ideas with Haraway's insight into vision and to Code's claim that facts do not self-announce. Both appear to be consistent with Tindale's rhetorical model, if taking it in directions he might not anticipate. The second, shorter, example, is from Jennifer Logue's work on the "will to ignorance" (Logue, 2008).

\section{Believing is seeing: engagement via non-agonistic playful- ness}

Critics sometimes present themselves as unable to "see" feminist positions, as if their eyes objectively and necessarily take in all the available evidence as evidence and find it wanting. The idea that what we are able to see can be a function of what we allow ourselves to see-which lenses we look through, for example - is a significant component of epistemologies of situated knowledges. Preparing for a philosophical discussion, arguers and audience will unthinkingly don their "philosophy lenses," focus on doing philosophy. This restricted eye, or deliberately focused vision, prevents the viewer from seeing what else is being presented that is beyond the lens's field of vision. Yet, just as it seems nearly impossible to not visualize a spotted frog when one reads the words "spotted frog," it seems nearly impossible for philosophers to leave their specific philosophy lens - and their limited ideas of feminism, for example - at home when doing philosophy. One way to escape this predicament could involve "tricking" philosophers into reading philosophy through different lenses.

Lugones suggests rhetorical techniques to engage privileged others that involve their fully situated selves through what she calls, non-agonistic playfulness and "world"-traveling (Lugones, 1987). Lugones describes agonistic playfulness as tied to a set definition of competence, where "you better know the rules of the game," which is about struggle, winners and losers (p. 15). Agonistic play is competitive, rather than collaborative, a zero-sum game where one's success turns on another's loss. However, a more

\footnotetext{
${ }^{19}$ Which will differ in strength, shape and effect for each person.
} 
skilled competitor might lose to a weaker opponent who knows and is better able to navigate the rules of the game. I suggest this describes adequately the way philosophical arguments on Moulton's description of the Adversary Method, for example, are typically played. Against this agonistic style of play, Lugones describes the kind of play children often engage in, where the object is play itself, rather than competing, keeping score, winning or losing. She cites the example of children playing with stones in a stream. They find that when they smash small stones, they reveal colorful interiors, so they play at "crashing stones for hours, anxious to see the beautiful new colors" (p. 15). Whereas uncertainty is central to agonistic play — who will win or lose? - in the non-agonistic style of play, she says,

The uncertainty is an openness to surprise. This is a particular metaphysical attitude that does not expect the world to be neatly packaged, ruly. Rules may fail to explain what we are doing... We are not wedded to a particular way of doing things. (pp. 16-17)

Philosophical argumentation is rarely playful in this sense, because usually the purpose is to remove uncertainty - which effectively defines winning - via exposing errors in the opponent's argument. Losing is embarrassing, as most of us who have been humiliated in a philosophy seminar will likely confirm, and being made the fool in this context can stiffen resolve to be more defensive and careful next time, further inhibiting "play." Yet, Lugones says that when playfulness is non-agonistic its participants are willing to leave themselves vulnerable, to bring "an openness to being a fool, which is a combination of not worrying about competence, not being selfimportant, not taking norms as sacred" (p. 17).

Given my comments, above, about the near-impossibility of philosophers being able to remove or replace a philosophical lens, the key to engaging them via this kind of playfulness can involve a certain amount of trickery, calling for the role of a "trickster."20 Imagine being cajoled or "tricked" into a kind of non-agonistic playful reading of texts that, as a traditionalist, I might not consider to be philosophy. This, I suggest, was a technique that worked on me as I slowly engaged with feminist epistemologies. My entry into this world or these worlds was, in part and mostly initially, via non-agonistic scholarly play. For example, rather than asking students to read a philosophical paper and summarize it in a two-page

\footnotetext{
${ }^{20}$ I take this term from Maureen Ford's usage, where she intends it in the sense of the Ojibway reference to the raven as "trickster." I acknowledge concerns by some women that "tricking and cajoling" can also bring to mind ways of negotiating with an oppressive partner and hope my context, above, does not invoke this usage.
} 
exegesis, Maureen Ford, for example, would sometimes change the rules. ${ }^{21}$ She might set this assignment: Read this (philosophy) paper and in response, write your interpretation of it as a fable. Next time, she may ask for a poem. Many students find this very difficult, not knowing which lens to wear, one for reading poetry or one for reading philosophy. I suggest here, in a very preliminary way, that one might ask a recalcitrant traditionalist to read Haraway's provocative work, "ecce homo" (Haraway, 1992), as a short story or as allegory. Perhaps, rather than requesting a rigorous pro forma linguistic analysis, one might ask for a description of the ways it holds together as a story, or for the ways characters are described. In the process, this technique can open a different entry point for engagement with the work, and one with anticipated subjective and varied outcomes - including the willingness to seem foolish (after all, we're just playing). However tenuous the engagement, this could be a way to take a novice more deeply into feminist work. With a nod to ESK's appreciation of testimony, I can attest that this technique worked well on me. At some point, I found myself in the material and without my protective analytical defenses. The more this happened, the more I allowed my eyes to see. In short, I slowly came to believe that feminist work is worth taking seriously and only then did I start to see its inherent legitimacy and the illegitimacy of my previous objections. Hence, my somewhat playful aphorism, "believing is seeing."

Importantly, however, I do not intend to imply that feminist work is merely playful or to be taken lightly, and I recognize that some could interpret as ingratiating the task of "sweetening" the content to make it more palatable. ${ }^{22}$ Rather, I suggest that playfulness in these kinds of contexts can be a very serious technique that could offer otherwise arrogant perceivers different lenses through which to engage with otherwise difficult material (for them). To the extent that some would find this demeaning I suggest that this is important and necessary work, since the goal is not about merely winning an argument, but reducing harm. Playfulness can open doors of perception, but coming to terms with what lies beyond the doors can be-and likely will be, for those who benefit from unexamined privilege - a painful experience. With pretentions to neutrality and objectivity stripped away, one is confronted with one's own complicity in harms produced on assumptions of neutrality and objectivity. Reflecting on power and privilege is one powerful key to the shift to feminist epistemologies of the type I have discussed in this paper and it presents an equally powerful challenge

\footnotetext{
${ }^{21}$ Here I invoke the rhetorical device of storytelling, recalling personal experiences with my professor, Maureen Ford in the context of several courses.

${ }^{22}$ I acknowledge that this terminology can be disturbing to some women, reminding them of having to cajole and "trick" their oppressive partners into not being abusive.
} 
to engagement. I offer here two suggestions that could help. First, again from Lugones, the idea of "world-traveling" (Lugones, 1987).

\section{3. 'World'-traveling}

This deceptively complex concept does not imply physical movement from one place to another, but a willingness for a person privileged by power (colour, gender, money, etc.) to be open to experiencing a subjugated person's world via their stories. From my own experience, moving from a traditionalist position to one that embraces feminist epistemologies was transformationaleffectively becoming a different person-which is consistent with Lugones's stated purpose:

The shift from being one person to a different person is what I call "travel." This shift may not be willful or even conscious, and one may be completely unaware of being different than one is in a different "world," and may not even recognize that one is in a different world. (p. 11)

She writes that a feeling of "being at ease in a world" is a way of knowing that it is "my world" (p. 13). Being a fluent speaker in one world is one indication of being at ease. Critics of feminist philosophy are usually fluent in the language of traditional epistemology, but feminist epistemologists have also usually been at home in the world of traditionalists prior to "traveling" to other worlds. However, the language of feminist epistemologists does not trip off the tongue for many traditionalists, who, rather than attempting to learn the language sometimes choose to simply describe it as incoherent nonsense.

I suggest that Lugones's work here could be a useful addition to rhetorical strategies: Rather than simply viewing positivistderived epistemology and feminist epistemologies as necessarily incommensurable, it may be helpful to see the respective positions as worlds in Lugones's terms and one approach to forging constructive conversations across differences could involve application of her idea of world traveling. As I mentioned, above, however, traveling to the world of feminist theory is not a weekend at Club Med for the privileged; when a person is finally able to see his or her complicity in harming others via hitherto unexamined power and privilege, the experience will be uncomfortable, humbling and often painful. In my concluding section, I offer one more sugges- 
tion for engaging dissenting traditionalists with "difficult" knowledges. ${ }^{23}$

\section{Will to ignorance}

On my interpretation of key aspects of ESK relative to the role of subjectivity, questioning the motivation of participants in philosophical argumentation becomes not only fair game, but, at times, a requirement. This is consistent with Tindale's claim that questioning the beliefs of the arguer is a legitimate component of rhetorical argumentation. Perhaps this could include a requirement for selfreflection, a need to ask of oneself, "How is it that I don't understand why they don't seem to understand my position?" This backhanded way of questioning one's own role in the impasse might better be put, "What does my ignorance do for me?"

Some may suggest that the answer to the question about why others don't "understand my position" could be willful ignorance. After all, feminists have produced an impressive body of work over the past three or more decades that seems hard to avoid unless one deliberately chose to do so. To my ear, however, the depiction of willful ignorance sets a deceptively benign tone that could bely the force of resisters' affective commitments in retaining their entrenched views. A better description, perhaps, would be something in line with Jennifer Logue's use of Nietzsche and Charles Mills to advance the idea of a "will to ignorance" (Logue, 2008). Much is made of the "will to knowledge," but Logue says that important work is accomplished via a will to not know, which she claims can be re-viewed as "neither a simple nor innocent lack of knowledge but as an active force of both psychic and social consequence that might help us to engage the resistance with which we are often met when dealing with difficult subjects." (p. 55). Logue is referring to ignorance of complicity in racism and social injustices, but I suggest her approach may well provide a tool for rhetorical engagement that invites self-interrogation. Some resisting traditionalists may well be prepared to ask themselves, as Logue cites Shoshana Felman: "Where does what I read or what I see resist my understanding? Where is the ignorance...located? What can I learn from the locus of that ignorance?" (p. 59). Were some otherwise resistant traditionalists open to merely asking themselves these questions, they would be demonstrating a belief, however weak and unformed, that the question is worth asking. Although my simple contention that believing is seeing requires a full examination and

\footnotetext{
${ }^{23}$ Megan Boler uses these terms in describing a "pedagogy of discomfort" wherein privileged students are invited to examine the role of privilege in their lives. (Boler, 1999)
} 
much more work, at this point I suggest that it could be a key to permitting the eye to expand its view and see what so many feminist epistemologists see all too clearly.

\section{Concluding Thoughts}

For those of us who present conference papers in feminist theory it can be disheartening to be partnered with a respondent who locks onto a single feature, reduces it to a propositional claim and then applies positivist-derived formal logic to attempt to discredit itwithout ever engaging with the overall purpose of the work. Instead of providing a review of the paper in terms of points of agreement and disagreement that could lead to a meaningful exchange of ideas, the respondent effectively uses this technique to establish the form the argumentation, setting rules for engagement that effectively dismiss the need to deal with the paper as a whole. On a frivolous level this is akin to refusing to discuss the movie Snow White until it is first proven that animals can speak English; or, perhaps more commonly, to refuse to discuss anything related to the Bible until the existence of God has been proved. Context is ignored to the detriment of all concerned. This is not to say that no feminist arguments can withstand rigorous critique; rather, the term "rigorous" needs to be re-described to require examination of context and details.

It is encouraging, therefore, that philosophers such as Tindale, especially, are producing compelling epistemological work in support of rhetorical argumentation models. By legitimizing goals of argumentation that allow for identifying areas of agreement and disagreement, as well for engaging the audience, Tindale, especially, creates rhetorical spaces that feminist epistemologists might use in presenting and defending their work, even if there are more points of disagreement than agreement when the discussion concludes. ${ }^{24}$

\footnotetext{
${ }^{24}$ As it happens, I recently used some of the ideas in this paper to nudge an argument toward a more rhetorical model in the discussion following a conference presentation of a paper on situated knowledges. My respondent, whose blisteringly negative written response reflected his admittedly logical positivist-derived epistemology, reported to me later that he had been moved via the experienceprimarily by the impassioned involvement of the audience - to take feminist theory more seriously and he promised to include one of Lorraine Code's books in the syllabus for his course in the coming year. See my paper and the response following it in: (Lang, 2010).
} 


\section{Acknowledgements}

I wish to thank Phyllis Rooney, Catherine Hundleby and two anonymous readers for this special issue of Informal Logic for their important comments and suggestions.

\section{References}

Boler, M. (1999). Feeling Power. New York: Routledge.

Code, L. (1987). Epistemic Responsibility. Hanover, NH: University Press of New England.

Code, L. (1991). What Can She Know? Ithaca, NY: Cornell University Press.

Code, L. (1995). Rhetorical Spaces: Essays on Gendered Locations. New York and London: Routledge.

Code, L. (2006). Ecological Thinking: The Politics of Epistemic Location. Oxford: Oxford University Press.

Ford, M. (1995). Being in the Known(N): Educational Implications of Situated Knowledges. University of Toronto, Toronto.

Ford, M. (2004). Considering the Standpoints of DifferentlySituated Others: Teachers and Arrogant Perception. In C. Higgins (Ed.), Philosophy of Education 2004 (pp. 347-345). Urbana: Philosophy of Education Society.

Frey, M. (1983). The Politics of Reality: Essays in Feminist Theory. Trumansburg, NY: Crossing Press.

Gilbert, M. A. (1997). Coalescent Argumentation. Mahwah, New Jersey: Lawrence Erlbaum Associates.

Haraway, D. J. (1992). Ecce Homo, Ain't (Ar'n't) I a Woman, and Inappropriate/D Others: The Human in a Post-Humanist Landscape. In J. Butler, Scott, Joan W. (Ed.), Feminists Theorize the Political (pp. 86-100). New York and London: Routledge.

Haraway, D. J. (2004/1988). Situated Knowledges: The Science Question in Feminism and the Privilege of Partial Perspective. In S. Harding (Ed.), The Feminist Standpoint Theory Reader: Intellectual and Political Controversies (pp. 81-101). New York and London: Routledge.

Hartsock, N. C. M. (2004 (1983)). The Feminist Standpoint: Developing the Ground for a Specifically Feminist Historical Materialism. In S. Harding (Ed.), The Feminist Standpoint Theory Reader: Intellectual and Political Controversies (pp. 35-53). New York and London: Routledge.

Kant, I. (1934). Critique of Pure Reason (J. M. D. a. P. Meicklejohn, Vasilis, Trans. 1993 ed.). London: J. M. Dent.

Kant, I. (1959). Foundations of the Metaphysic of Morals and What Is Enlightenment? (L. W. Beck, Trans.). Indianapolis, New York, Kansas City: The Bobbs-Merrill Company, Inc. 
Keller, E. F. (1983). Gender and Science. In S. a. H. Harding, Merill B. (Ed.), Discovering Reality (pp. 187-205). Boston: D. Reidel Publishing Company.

Lang, J. C. (2010). Educational Epistemic Ecosystems: ReVisioning Educational Contexts on Code's "Ecological Thinking". In Philosophy of Education 2010. Urbana, Illinois: Philosophy of Education Society.

Logue, J. (2008). The Unbelievable Truth and the Dilemmas of Ignorance. In R. D. Glass (Ed.), Philosophy of Education (pp. 54-62). Urbana: Philosophy of Education Society.

Lugones, M. (1987). "Playfulness," 'World'-Travelling, and Loving Perception". Hypatia, 2(2), 3-18.

Mackenzie, C. (2000a). Imagining Oneself Otherwise. In C. Mackenzie, and Stoljar, Natalie (Ed.), Relational Autonomy: Feminist Perspectives on Autonomy, Agency, Andthe Social Self (pp. 124-150). Oxford: Oxford University Press.

Mackenzie, C., Stoljar, Natalie. (2000b). Autonomy Refigured. In C. Mackenzie, and Stoljar, Natalie (Ed.), Relational Autonomy: Feminist Perspectives on Autonomy, Agency, and the Social Self: Discourses of Social Advocacy at Century's End (pp. 3-31). Oxford: Oxford University Press.

Moulton, J. (1983). A Paradigm of Philosophy: The Adversary Method. In S. a. H. Harding, Merill B. (Ed.), Discovering Reality (pp. 149-164). Boston: D. Reidel Publishing Company.

Sandoval, C. (2004). U.S. Third World Feminism: The Theory and Method of Differential Oppositional Consciousness. In S. Harding (Ed.), The Feminist Standpoint Reader (pp. 195-209). New York and London: Routledge.

Siegel, H. (2008). A Symposium on Epistemology and Education: Introduction. Educational Theory, 58(2), 123-124.

Tindale, C. W. (1999). Acts of Arguing. New York: State University of New York Press.

Tuana, N. (2001). Material Locations: An Interactionist Alternative to Realism/Social Constructivism. In N. Tuana, and Morgen, Sandra (Ed.), Engendering Rationalities (pp. 221-243). Albany: SUNY Press.

White, P. (2010, February 13). Unrepentent 'Nazi Mom' Aims to Get Her Kids Back. The Globe and Mail, p. 18.

Young, I. M. (1997). Asymmetrical Reciprocity: On Moral Respect, Wonder, and Enlarged Thought. In Intersecting Voices: Gender, Political Philosophy, and Policy (pp. 35-89). Princeton: Princeton University Press. 